\title{
The equine nasopharynx in dynamic upper airway disorders: an update
}

\author{
Caroline Tessier \\ Pferdeklinik, Tierspital Universität Bern, Berne, Suisse
}

\begin{abstract}
Summary
The nasopharynx is a source of several upper airway disorders such as dorsal displacement of the soft palate, pharyngeal lymphoid hyperplasia and pharyngeal collapse. The neuromuscular anatomy of this region is complex and the etiology of these diseases is poorly understood. Recently, progress has been made to understand and elucidate the pathophysiology of these disorders. The aim of this review is to give an overview of the recent advances in this area.
\end{abstract}

Keywords: nasopharynx, pharyngeal collapse, dorsal displacement of the soft palate, pharyngeal lymphoid hyperplasia.

\section{Der Nasopharynx des Pferdes bei dynamischen Erkrankungen der oberen Atemwege - ein Update}

Seit Einführung der Videoendoskophie auf Hochgeschwindigkeits-Laufbändern hat sich die Diagnostik von dynamischen Obstruktionen der oberen Atemwege verbessert. Trotzdem bleiben Pathophysiologie und Behandlungsmöglichkeiten unklar. Obstruktionen des Nasopharynx scheinen unter diesen Problemen besonders anspruchsvoll.Der Nasopharynx des Pferdes ist eine anatomisch und funktionell komplexe Struktur. Spezifische Muskelgruppen sind verantwortlich für Dilatation und Kontraktion. Diese Muskeln wiederum werden innerviert von verschiedenen Nerven einschliesslich der Hirnnerven V, IX, X und XII. Ausserdem sind Mechanorezeptoren der Pharynxschleimhaut an der Erkennung der Luftbewegung, der Muskelmobilisierung und der Luftwegserweiterung beteiligt. Neuere Studien haben die Beteiligung bestimmter Muskeln an der Aetiologie von nasopharyngealen Erkrankungen aufgezeigt. Die Dorsalverlagerung des weichen Gaumens wurde in Verbindung gebracht mit der Fehlfunktion des Musculus thyroideus, der Musculi veli palatini und dem Musculus palatinus. Durch die Leitungsanästhesie des pharyngealen Astes des Nervus vagus konnte ein experimentelles Model für die Dorsalverlagerung des weichen Gaumens kreiert werden. Trotz dieser Fortschritte die Pathogenese der Dorsalverlagerung des weichen Gaumens ein ungenügend verstandenes, multifaktorielles Geschehen. Verschiedene Behandlungen mit unterschiedlichen Erfolgsraten sind für diese Erkrankung propagiert worden. Jüngst konnte der dorsale nasopharyngeale Kollaps experimentell reproduziert werden, wobei die Fehlfunktion des Musculus stylopharyngeus eine mögliche Ursache zu sein scheint. Bis anhin gibt es keine Therapie für den dorsalen nasopharyngealen Kollaps. Pharyngitis wird beim Pferd oft angetroffen und ist bedingt durch entzündliche Atemwegsinfekte durch verschiedene infektiöse Erreger, sowie durch die Aufstallung und das Alter des Pferdes. Kontrollierte Studien fehlen, aber ausser in ihrer hochgradigen Form, scheint die follikuläre Pharyngitis keinen Einfluss auf die Leistung zu haben. Allerdings könnte sie ein Wegbereiter für andere dynamische Atemwegsobstruktionen, wie die Dorsalverlagerung des weichen Gaumens, sein. Das Ziel dieses Artikels ist es, die neuromuskuläre Anatomie des Nasopharynx zu beschreiben und einen Überblick über die Fortschritte im Verständnis der Pathophysiologie des Nasopharynx zu geben.

Schlüsselwörter: Pferd, Nasopharynx, pharyngealer Kollaps, dorsale Verlagerung des weichen Gaumens, follikuläre Pharyngitis.

\section{Introduction}

The advent of high-speed treadmill examination opened a whole new world to the eyes of equine veterinarians. We are now able to recognize several dynamic upper airway disorders that are present predominantly or exclusively during exercise, such as dorsal displacement of the soft palate, pharyngeal collapse, axial deviation of the aryepiglottic folds, epiglottic entrapment, epiglottic retroversion (Martin 2000). Therefore, high-speed treadmill examination has been recommended to evaluate horses presenting for poor performance with or without respiratory noise (Lumsden 1995). Although our knowledge of dynamic upper airway obstructions has increased, many new questions about the etiology of these diseases have arisen. Because of their dynamic and multifactorial nature, these problems are difficult to diagnose and treat effectively. Furthermore, the pathogenesis of dynamic upper airway obstruction remains enigmatic in some diseases, especially those affecting the nasopharynx. Considerable efforts have been made worldwide by research groups to recognize these disorders, understand their etiologies and clinical significance, and offer specific therapies. These research groups have shown that specific neuromuscular entities were responsible for control of nasopharyngeal patency and have thus enabled us to better understand the complex neuromuscular anatomy of the nasopharynx. The aim of this review article is to provide an overview of the latest advances in the understanding, diagnosis and treatment of dynamic nasopharyngeal obstructions.

\section{Anatomy of the nasopharynx and the pharyngeal musculature in horses}

The pharynx is a musculo-membranous tube that shares digestive and respiratory functions. Because their soft palate contacts the epiglottis, horses have no functional communication between their oro- and nasopharynx. They are therefore obli- 
gate nasal breathers. The pharynx is a funnel-shaped chamber contained between the base of the skull and first couple of cervical vertebrae dorsally, the larynx ventrally, and the pterygoid muscles, the mandible and the dorsal part of the hyoid apparatus laterally. The nasopharynx is about $15 \mathrm{~cm}$ long and its long axis is directed downward and backward. It is attached by its muscles to the palatine, pterygoid, and hyoid bones, and to the cricoid and thyroid cartilages of the larynx. However, the nasopharynx is not directly supported by bony structures and is therefore susceptible to considerable deformation by the negative pressures occuring during inhalation. Its principal relations are: dorsally, to the base of the cranium and guttural pouches; ventrally, to the larynx and soft palate, the latter extending caudally from the hard palate to the base of the larynx and forming the floor of the nasopharynx, and laterally, to the medial pterygoid muscle, the great cornu of the hyoid bone, the external carotid and external maxillary arteries, the glossopharyngeal, anterior laryngeal, and hypoglossal nerves, the mandibular salivary gland, and the parapharyngeal lymph glands (Sisson 1976).

Two groups of muscles modify the shape and diameter of the pharyngeal opening: intrinsic pharyngeal muscles that form the walls of the nasopharynx and extrinsic pharyngeal muscles whose action will also deform the nasopharynx. The intrinsic muscle group is composed of: cricopharyngeus, hyopharyngeus, thyropharyngeus, palatopharyngeus, pterigopharyngeus and stylopharyngeus. These muscles are responsible for constriction and dilation of the nasopharynx (Sisson and Grossman 1976). The cricopharyngeus muscle originates on the lateral aspect of the cricoid cartilage and attaches on the median raphe. The hyopharyngeus muscle attaches on the hyoid bone and ends at the median raphe, and the thyropharyngeus muscle originates on the lateral lamina of the thyroid cartilage and inserts on the median raphe. These three muscles are pharyngeal constrictors and their shortening depresses the pharyngeal walls down and inward. The palato-pharyngeus arises on the aponeurosis of the soft palate and inserts partly into the upper edge of the thyroid cartilage and partly on the median raphe. The pterygo-pharyngeus muscle lies on the anterior part of the lateral wall of the pharynx. During the act of swallowing, both of these muscles act to shorten the pharynx and to draw the larynx and esophagus toward the root of the tongue. The stylopharyngeus muscle arises from the medial surface of the great cornu of the stylohyoid bone, passes ventromedially and enters the wall of the pharynx by passing between the pterygo-pharyngeus and the palato-pharyngeus muscles. Its fibers radiate, many bundles passing forward, others inward or backward beneath the hyopharyngeus. It raises and dilates the pharynx to receive the bolus in swallowing (Sisson 1976). In people, it is known that contraction of the stylopharyngeus muscle also dilates the dorsal part of the nasopharynx (Kuna and Vanoye 1999).

The extrinsic muscles are part of the hyoid apparatus: geniohyoid, genioglossus, sternohyoid, sternothyroid and hyoepiglotticus muscles. The hyoid apparatus is attached to the petrous temporal bone and supports the root of the tongue, pharynx and larynx. The basihyoid bone is closely related to the base of the tongue via its attachments to the genioglossus and hyoglossus muscles. It articulates with the short ceratohyoid bone located just cranial to it. The latter joints the stylohyoid bone, which extends from the skull cranially. Forward and downward movement of the tongue will therefore enlarge the nasopharynx by extending the ceratohyoid-stylohyoid articulation, thus enlarging the dorsoventral diameter of the nasopharynx.

\section{Pharyngeal lymphoid hyperplasia}

The high incidence of pharyngeal lymphoid hyperplasia in young horses has been well documented. The cause and significance of this affection, however, remains unclear.

The mucosa of the equine respiratory system is a critical defense mechanism but can also be involved in pathologic conditions such as pharyngeal lymphoid hyperplasia. At a microscopic level, the pharyngeal mucosa is composed of pseudostratified columnar epithelium studded with goblet cells, lymphoid follicles and sensory receptors of the glossopharyngeal and trigeminal nerve. These receptors are mostly tactile, involved in airway protection, for airflow detection and in eliciting the gag reflex. Studies have shown that topical anesthesia of the laryngeal mucosa caused increased inspiratory upper airway pressures and nasopharyngeal impedan$c e$, and decreased peak tracheal inspiratory pressure, respiratory frequency and minute ventilation Holcombe et al. 2001 a). Nasopharyngeal collapse also occurred in all horses during exercise after local anesthesia of the laryngeal mucosa. The authors concluded that the receptors present in the laryngeal mucosa were important in maintaining normal patency and function of the nasopharynx in exercising horses. The nasopharyngeal tonsil is considered as an important site for mucosal immune induction (Kumar et al. 2001). The pharyngeal mucosa also harbors many etiologic agents of upper and lower respiratory tract infections.

In a study showing the progression of PLH in growing foals between birth and 11 months of age, which were housed under different conditions, it appeared that the occurrence of PLH could be seen as a normal developmental phenomenon but was influenced by housing conditions (Sloet 2000). Stabling and in particular increased concentrations of organic dust in the environment was a predisposing factor in another study (Holcombe et al. 2001b). Many authors consider that, unless severe, pharyngeal lymphoid hyperplasia does not significantly affect horses' performance (Sullivan and Parente 2003). In one study, it was shown that PLH does not inhibit gas exchange during exercise unless the lesions were extremely severe (Bayly 1984). In an artificial airway model, it seems that severe PLH could interfere with airflow distal to the site of the lesion during high frequency high volume ventilation (Bayly 1997). However, there are no studies looking at the effect of PLH on upper airway pressures or flow-volume loops. As PLH seems to resolves with age, it also appears that the incidence of some dynamic upper nasopharyngeal obstructions also decreases as the horse ages. It has been shown that retropharyngeal lymphadenopathy could be causing neural inflammation of the pharyngeal branch of the vagus nerve. It is then probable that pharyngitis could lead to dysfunction of the pharyngeal mechanoreceptors located within the pharyngeal mucosa and disturb normal nasopharyngeal function. Furthermore, some authors recommend to treat pharyngeal inflammation and let young horses mature before attempting to specifically address upper airway disorders (Ducharme 2006). 


\section{Dorsal displacement of the soft palate (DDSP)}

A perfect example of the complexity of the equine nasopharynx is the intermittent dorsal displacement of the soft palate. Although this disease is well accepted as a performance limiting problem, its diagnosis and treatment remain an unresolved issue.

This problem more commonly affects young horses (Parente et al. 2002, Ducharme 2006). In one study evaluating results of endoscopy of the upper respiratory tract during treadmill exercise in 100 horses, 20 horses showed DDSP (Kannegieter and Dore 1995). The clinical signs are exercise intolerance and abnormal respiratory noise (Sullivan and Parente 2003). It has been shown that $80 \%$ of horses presenting DDSP during treadmill examination did not have any abnormalities detected during resting endoscopy. Also, 38\% of horses that presented DDSP during exercise did not have any history of respiratory noise (Parente 2002).

The pathogenesis of DDSP is still uncompletely understood. Many hypotheses have been proposed to explain this phenomenon: e.g., epiglottic flaccidity/deformation, caudal retraction of the larynx, overly long soft palate, and others. DDSP can be experimentally created by bilateral local anesthetizia of the pharyngeal branch of the vagus nerve within the guttural pouch, which causes the soft palate to displace dorsally, producing expiratory obstruction (Holcombe et al. 1998). This led to the hypothesis that retropharyngeal neuropathy could be responsible for neural dysfunction of the pharyngeal branch of the vagus nerve and cause DDSP in clinical cases.

Holcombe and coworkers also showed that experimentally induced epiglottic retroversion did not cause DDSP, questioning the validity of epiglottic augmentation procedures in the treatment of DDSP (Holcombe et al. 1997). Ducharme et al. (2003) have shown that intermittent DDSP could also be created experimentally by transecting the thyrohyoid muscles. The function of the thyrohyoid muscles is to draw the larynx forward and the basihyoid bone caudally. By restoring the function of the $\mathrm{TH}$ muscles using a prosthetic suture, the same research group was able restore normal soft palate function in a $80-82 \%$ of horses clinically affected by DDSP (Woodie 2005). Furthermore, DDSP can be associated with other nasopharyngeal disorders. In 92 horses diagnosed with dorsal displacement of the soft palate (DDSP) during treadmill video-endoscopy, 11 had associated dynamic pharyngeal collapse (Parente et al. 2002).

Rostral pharyngeal collapse is also seen in young horses and has been described as a precursor phenomenon to DDSP. This condition can be reproduced experimentally by bilaterally transecting the tendon of the tensor veli palatini (Holcombe et al.1999). However, rostral pharyngeal collapse is an inspiratory obstruction and when created experimentally, it only causes minor airway obstruction.

\section{Nasopharyngeal collapse}

Nasopharyngeal collapse is a disease observed in adult horses that causes upper airway obstruction, exercise intolerance and abnormal upper respiratory noise. While some horses affected by nasopharyngeal collapse will show signs of upper airway obstruction and/or abnormal noise at rest (Smith 1994), the majority of them will exhibit clinical signs only during exercise, making the condition difficult to diagnose. Poor performance and abnormal respiratory noise are some of the owner's common complaints. The features accompanying this disease are dorsal pharyngeal collapse and collapse of the lateral walls of the nasopharynx. Dorsal pharyngeal collapse can be uni- or bilateral (Smith 1994).

Use of high-speed treadmill endoscopy as a diagnostic tool has improved our recognition of the disease. Reported prevalence rates vary from 3 to 29\% (Kannegieter and Dore 1995, Martin et al. 2000, Dart et al. 2001, Durando et al. 2002). In one study, 40 out of 256 horses presented for poor performance had pharyngeal collapse. Thirty of 40 horses with pharyngeal collapse had abnormal upper airway noise that was inspiratory and best heard early or late in the exercise cycle. Collapse of the pharyngeal walls obstructed part or most of the tracheal opening (Martin et al. 2000).

Recently, the stylopharyngeus muscle has been recognized as playing a key-role in the etiology of dynamic nasopharyngeal collapse in horses. This small muscle originates on the stylohyoid bone and attaches to the dorsal roof of the nasopharynx (Fig. 1). We have shown that by anesthetizing the glossopha-

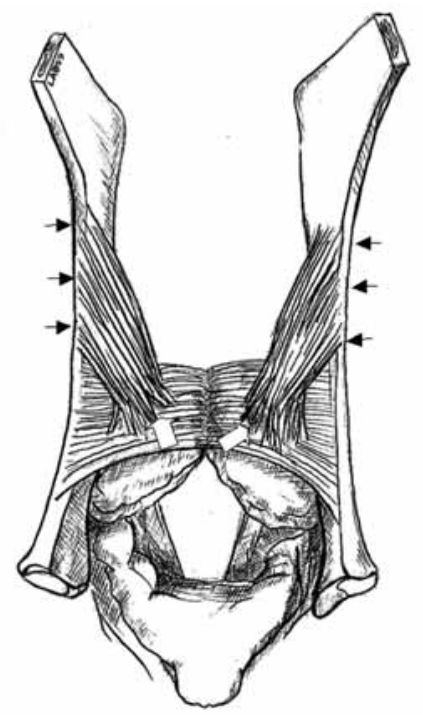

Fig 1 Drawing showing the origin of the stylopharyngeus muscle on the stylohyoid bone (black arrows) and its attachments (white arrows) onto the dorsal nasopharyngeal wall.

Die Zeichnung zeigt den Ursprung des M. stylopharyngeus am Stylohyoid (schwarze Pfeile) und seine Anheftung an der dorsalen Wand des Nasopharynx (weiße Pfeile).

ryngeal nerve bilaterally and thus blocking the afferent motor innervation to the stylopharyngeus muscle, we could create dynamic dorsal pharyngeal collapse (Fig.2) and upper airway obstruction in experimental horses (Tessier et al. 2004). Furthermore, the electromyographic activity of the stylopharyngeus muscle has been investigated in normal exercising horses. The results of this study demonstrated that the stylopharyngeus muscle has a phasic inspiratory and tonic activity that increases with speed in exercising horses. This was consistent with the proposal that contraction of the stylopharyngeus muscle supports the dorsal nasopharyngeal wall in exercising horses. (Tessier et al. 2005) The stylopharyngeus, similar to many 
other upper airway dilating muscles, maintains activity throughout the breathing cycle. In normal awake goats, the stylopharyngeus muscle was found to exhibit tonic expiratory and phasic inspiratory activity, whereas the pharyngeal constrictors

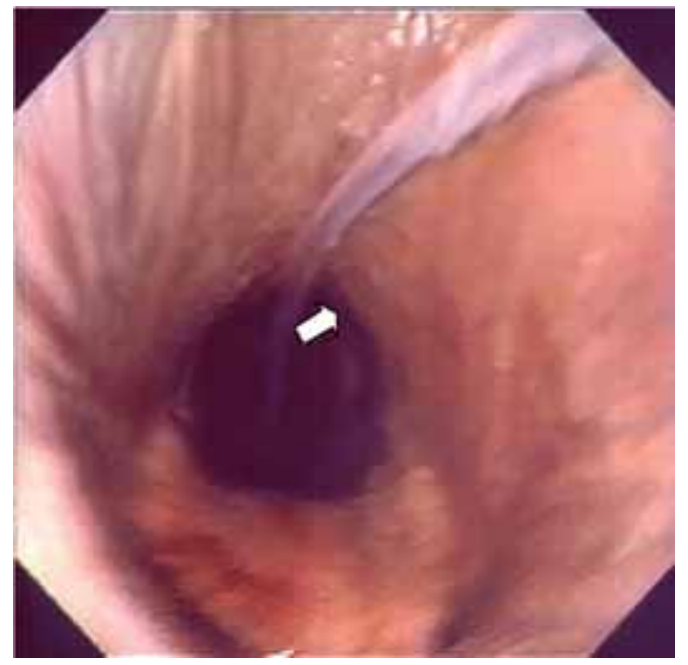

Fig 2 Video-endoscopic picture of a horse after bilateral anesthesia of the glossopharyngeal nerve, with an intra-tracheal catheter in place. The horse developed dorsal pharyngeal collapse during exercise. Notice that the roof of the nasopharynx descends below the level of the corniculate processes of the arytenoids cartilages (arrow). Endoskopisches Bild eines Pferdes nach bilateraler Anästhesie des N. glossophangicus. Das Pferd entwickelte einen Pharynxkollaps unter der Arbeit (Pfeil).

were active during expiration. This duality of action allows the nasopharynx to adapt its size and shape to the airflow and resist collapse when large negative pressures are applied to the upper airway (Feroah et al. 2000).

\section{Conclusion}

The patency of the nasopharynx is influenced by the activity of intrinsic muscles but also by extrinsic structures. It is evident that the intrinsic nasopharyngeal musculature and its associated nerves are very important actors in the etiology of nasopharyngeal diseases. We need to know more about how these muscles are recruited during effort in the horse, in what sequence, and what are the receptors implicated in muscle activation to understand the pathogenesis of nasopharyngeal disorders. In addition, we have been able to show the involvement of specific muscles into the pathogenesis of these diseases but we have very limited ways of imaging them. The key to this question could be modern diagnostic imaging such as ultrasound or MRI.

\section{References}

Bayly W. M., Grant B. D. and Breeze R. G. (1984): Arterial blood gas tension and acid base balance during exercise in horses with pharyngeal lymphoid hyperplasia. Equine Vet J. 16, 435-438

Bayly W. M. and Slocombe R. F. (1997): Airflow mechanics in models of equine obstructive airway disease under conditions simulating exercise. Res Vet Sci. 62, 205-21 1

Dart J. A., Dowling B. A., Hodgson D. R. and Rose R. J (2001) Evaluation of high speed treadmill videoendoscopy for diagnosis of upper respiratory tract dysfunction in horses. Aust Vet J. 79, 109-112

Ducharme N. G. (2006): Pharynx. In: Auer and Stick, editors: Equine Surgery, Philadelphia, WB Saunders
Ducharme N. G., Hackett R. P., Woodie J. B., Dykes N., Erb H. N., Mitchell L. N. and Soderholm L. V. (2003): Investigations into the role of the thyrohyoid muscles in the pathogenesis of dorsal displacement of the soft palate in horses. Equine Vet J. 35, 258-263

Durando M. M., Martin B. B., Hammer E. J., Langsam S. P. and Birks E. K. (2002): Dynamic upper airway changes and arterial blood gas parameters during treadmill exercise. Equine Vet. J. Suppl. 34, 408-412

Feroah T. R. et al. (2000): Reciprocal activation of hypopharyngeal muscles and their effect on upper airway area. J. Appl. Physiol. 88, 61 1-626

Holcombe S. J. (1997): Effects of bilateral hypoglossal and glossopharyngeal nerve blocks on epiglottic and soft palate position in exercising horses. Am J Vet Res. 58, 1022-1026

Holcombe S. J. (1998) Effect of bilateral blockade of the pharyngeal branch of the vagus nerve on soft palate function in horses. Am J Vet Res. 59, 504-508

Holcombe S. J., Derksen F. J., Stick J. A. and Robinson N. E. (1999) Pathophysiology of dorsal displacement of the soft palate in horses. Equine Vet J Suppl. 30, 45-48

Holcombe S. J., Jackson C., Gerber V., Jefcoat A., Berney C., Eberhardt S. and Robinson N. E. (2001a): Stabling is associated with airway inflammation in young Arabian horses. Equine Vet J. 33, 244-249

Holcombe S. J., Derksen F. J., Berney C., Becker A. C. and Horner N. T. (2001 b): Effect of topical anesthesia of the laryngeal mucosa on upper airway mechanics in exercising horses. Am. J. Vet. Res. 62, 1706-1710

Kannegieter N. J. and Dore M. L. (1995): Endoscopy of the upper respiratory tract during treadmill exercise: a clinical study of 100 horses. Aust Vet J. 72, 101-107

Kumar P., Timoney J. F. and Sheoran A. S. (2001): M cells and associated lymphoid tissue of the equine nasopharyngeal tonsil. Equine Vet J. 33, 224-230

Kuna S. T. and Vanoye C. R. (1999): Mechanical effects of pharyngeal constrictor activation on pharyngeal airway function. J Appl Physiol 86, $411-417$

Lumsden J. M., Stick J. A. and Caron J. P. (1995): Upper airway function in performance horse: videoendoscopy during high speed treadmill exercise. Comp Contin Educ Pract Vet 17, 1134-1145

Martin B. B. Jr., Reef V. B., Parente E. J. and Sage A. D. (2000): Causes of poor performance of horses during training, racing, or showing: 348 cases (1992-1996). J Am Vet Med Assoc. 216, 554-558

Parente E. J., Martin B. B., Tulleners E. P. and Ross M. W. (2002): Dorsal displacement of the soft palate in 92 horses during high-speed treadmill examination (1993-1998). Vet Surg. Nov-Dec 31, 507-512

Sloet van Oldruitenborgh-Oosterban M. M., Gruys E. and van Duijkeren E. (2000): Developmental aspects of follicular pharyngitis and laryngeal hemiplegia in the foal. In: Proceeding of the Annual Convention of the American Association of Equine Practitioners 46, 270-273

Smith C. J., Taylor R. J. and Dixon P. M. (1994): Unilateral ventral displacement of the roof of the nasopharynx as a cause of a stridor in a pony. Vet. Record 134, 140-141

Sisson and Grossman (2003): Anatomy of the Domestic Animals 5th edition vol. 1 WB Saunders

Sullivan E. K. and Parente E. J. (2003): Disorders of the pharynx. Veterinary clinics of North America, Equine practice. 19, 159-167

Tessier C., Holcombe S. J., Derksen F. J., Berney C. and Boruta D. (2004): Effects of stylopharyngeus muscle dysfunction on the nasopharynx in exercising horses. Equine Vet J. 36, 318-323

Tessier C., Holcombe S. J., Stick J. A., Derksen F. J. and Boruta D. (2005): Electromyographic activity of the stylopharyngeus muscle in exercising horses. Equine Vet J. 37, 232-235

Widmer A. (2004): The influence of inflammatory airway disease on the performance of sport horses" Vet. Med. Diss. Universität Bern

Woodie B., Ducharme N. G., Kanter P., Hackett R. P. and Herb H. N. (2005): Surgical advancement of the larynx (laryngeal tie-forward) as a treatment for dorsal displacement of the soft palate in horses: a prospective study 2001-2004. Equine Vet J. 37, 418-423

Dr. Carolone Tessier MS, DACVS, DECVS

Pferdeklinik, Tierspital Universität Bern

Längassstrasse 124, CH-3012 Berne, Suisse

carolin.tessier@knp.unibe.ch 